Journal of Professional Counselling and Psychotherapy Research (JPCPR) Volume III, Issue 1

\title{
A BRIEF PROPENSITY INDEX FOR CONDUCT DISORDER (BPI-CD): DEVELOPMENT, VALIDITY AND RELIABILITY
}

\author{
${ }^{* 1}$ Oguntayo, Rotimi, ${ }^{2}$ Olaseni Abayomi, O., ${ }^{3}$ Kehinde, Miracle O., ${ }^{4}$ Osinowo, Helen. O., \& \\ ${ }^{5}$ Yakubu, Isaa, I. \\ 1,2,3 \& 5 Department of Psychology, Faculty of Social Science, University of Ilorin, Nigeria \\ ${ }^{4}$ Department of Psychology, The Faculty of Social Science, University of Ibadan, Nigeria \\ Corresponding Author: rotimijoguntayo@gmail.com \\ Phone Number: +2348060748460
}

\begin{abstract}
Conduct Disorder (CD) can pose serious concerns to parents, home and the society, meanwhile assessing this construct in clinical practice has been based on western concepts which limited the cultural factors implicated in CD. This study presents a reliable and valid screening tools for conduct disorder among juveniles and general population respectively. Existing scales that assessed deviant behavior or $\mathrm{CD}$ were reviewed. A qualitative study was conducted using juveniles and college students between the age 10 to 19; this is to determine salient constructs related to CD. Themes were generated, and those related to specific predictors of CD were used to generate a 17item of Brief Propensity Index for Conduct Disorder (BPI-CD). A cross-sectional survey was then conducted among 125 juveniles and college students to assess the reliability and validity of the scale. The participants were purposively selected. Construct validity using exploratory factor analysis was factored and Varimax rotated the scale into six components $(\mathrm{KMO}=.685, \mathrm{df}=171$, $\mathrm{p}<.001)$. Convergent validity results showed a significant relationship between BPI-CD and Youth Deviant Behavior Variety Scale ( $\mathrm{r}=.338, \mathrm{p}<.01)$, while discriminant validity results revealed a nonsignificant relationship between (BPI-CD) and Social Skills Scale ( $r=.101, p>.05)$, thus showing a strong validity. The reliability dimensions and subscales have meritorious reliability (Aggression to People/Animals, $\alpha=.76$, Serious Violation of rule and destruction of property, $\alpha=.73$; Deceitfulness and theft, $\alpha=.68$ ). The overall Cronbach's Alpha was 0.86. BPI-CD is therefore recommended as reliable and valid screening tool for conduct disorder tendency.
\end{abstract}

Keywords: Adolescents, Brief Propensity Index for Conduct Disorder, Juveniles, Delinquencies.

\section{INTRODUCTION}

Delinquency and Conduct disorder (CD) are complicated behavioural and emotional problems in children and adolescents that can pose serious concerns to parents, home and the society. It is characterized by recurrent and a persistent behavioural disorder that occurs during childhood and adolescence stage, in which the basic rights of others or major ageappropriate societal norms or rules are violated. According to American
Psychological Association (APA; 2015), conduct disorder is a repetitive and persistent pattern of behaviour which involves; being aggressive to humans and animals, deception, and destructive behaviours that usually begin in childhood or adolescence. They are behaviours that violate the basic rights of others with disorderliness, rebelliousness and deceitfulness and unaccepted societal rules (Adeusi, Gesinde, Alao, Adejumo \&Adekeye, 2015). Conduct disorder has been identified as a major 
psychiatric, legal and psychological behaviour problem among youths which have been causing serious concern to every communities and across the country (Agboola, Babalola \& Udofia, 2017; Nwankwo, Nwoke, Chukwuocha, Obbany, Nwoga, Iwuagu, \& Okereke, 2010).

Nwankwo et al., (2010) further explained that, Clinical practice and studies among Nigerian psychiatrist and psychologists on Conduct Disorder (CD) has been based on western researchers' studies of their own societies and its behavioral implications on individuals; therefore, generalizing such results to African settings might be a gross flaw especially due to the diverse ideological and cultural orientation that characterize Nigerian societies. This will cause catastrophic consequences especially in the understanding and classification of normal and abnormal behaviors; whereby several cultural norms as well as religious doctrines will be abolished and stereotyped among western-receptive societies. This will also have adverse effects on the development of appropriate measurements as well as concurrent validity and reliability of psychological scales for measuring conduct disorder due to the fact that a faulty ideology was applied in understanding Africans; therefore, pragmatic steps has to be taken to remedy the psychometry of instruments on conduct disorder so that it can have the local reliability and validity.

Conduct disorder prevalence, aetiology, predictors, and methods of intervention have been reported via diverse researches (Agboola, et al., 2017). Accurate or up-to-date information on the prevalence of conduct disorder is imperative in that it would serve as baseline data for preventive and remediative strategies. However, from in-depth review of the literature, obtaining accurate statistics on the prevalence of conduct disorder is next to difficult task especially in developing countries of the world (Adeusi, et al., 2015; Agboola, et al., 2017; Nwankwo, et al., 2010). In Nigeria, for instance, quite a number of adolescents are in correctional homes mainly for conduct disorder offence but investigation on prevalent level and degree of severity of their conduct disorder is comparatively unknown (Adeusi, et al., 2015).

This investigation is of high necessity because conduct disorder has not only been found to have four core symptom clusters but has also been found to be influenced by gender, parental socio-economic status, and parenting style (Adeusi et al, 2015). Applying the right medication to a wrong diagnosis of illness will placate the problem and in the case of conduct disorder, the inability to use the culturally consistent instrument has been a problem and the inability to drastically validate and restandardize current instruments will be another potential problem. A measure that will consider, the cultural specificity and the existing public attitudes towards, $C D$ is therefore imperative. To the best of our knowledge, there is a dearth of a Nigerian psychometrically developed tool to measure CD. Therefore, this study seeks to fill the gaps stated above. Consequently, the approaches to scale creation will be discussed to buttress the process utilized in the development of the current scale.

There are two different approaches to scale development, a deductive approach does focus the use of theory and the alreadyexisting concepts of construct to generate items within its literature domain. This approach is useful when the definition of the construct is known and substantial enough to generate an initial pool of items (Tay \& Jebb, 2017). In other way round, an inductive approach is most useful when there is uncertainty in the description, operationality or dimensionality of a construct. In this case, 
experts or organizational incumbents are consulted to provide definitions of the construct and such concept are conceptualized and then derived; so that this could forms the basis for generating items (Tay et al., 2017).

Exploratory approach or concept work to specifically identify the items and the dimensions of construct in a scale, exploratory factor analysis (EFA) is the most widely used approach in examining reliability of a new scales. Factor analysis is a group of statistical structure analyzing procedures used to identify correlations among observable variables to enhance reduction in the data of variables correlated with each dimension of the scale (i.e., factor) of the construct (Norris \& Lecavalier, 2010). Usefully, EFA explores the data and gives direction or guidance on factor number. In a confirmatory factor analysis (CFA), researchers specifically identify factor number and the related variables with each factor prior to conducting one. EFA is essentially recommended over CFA for scale development due to the possibility that scholars may be incorrect regarding their assumptions about the construct's dimensionality and to also ascertain the quality of the items. It is essential that CFA should be conducted on a separate sample to confirm the structure of the proposed scale resulting from an EFA (Kline, 2013; Worthington \& Whittaker, 2006).

Looking at the essentiality of induction, deduction and exploratory approaches to scale development; scholars should never be to careless to assume the rigor of published scales. All published scales should be subjected to a confirmatory factor analysis to validate the domain structure of an instrument so that faulty literature will be prevented and robust and valid scales will be built to create efficiency and effectiveness which will aid generalization and internal consistency (Levine, Hullett, Turner, \& Lapinski, 2006). The difficulty being experienced in the scale development and scale validation can result in several misleading and missteps if normal approaches are not being utilized; the current scale development undergone a thorough and sequential informational process to achieve a reliable and valid scale for use in both clinical and general population settings.

\section{Methods}

\section{Participants}

For the qualitative study where items were generated, those who participated in the Focus Group Discussion (FGD) that informed the themes generated were 24 juveniles in Welfare Home in Ilorin, Kwara State, Nigeria and one social worker was granted a key informant interview in the same institution. The Juveniles who assented to participate in study were grouped thus; 6 participants were in FGD1, 8 participants were in FGD 2 and 10 participants were in FGD 3. During the survey study, a sample size of 125 respondents were selected purposively. The respondents involved $60(48.0 \%)$ juveniles from Borstal correctional institution in Ilorin and $65(52.0 \%)$ secondary school students (general population) in Ilorin south local government in Ilorin, Nigeria. They were from different tribes within Nigeria. It was observed that there were $40(32.0 \%)$ female and $85(68.0 \%)$ male respondents. In terms of religion, $67(53.6 \%)$ were Christians and $58(47.4 \%)$ were Muslims. 


\section{Instrument}

Items Generation and Selection:

Firstly, the researcher reviewed the literature to examine the existing scales that measured conduct disorder and factors influencing it. Secondly, the researcher conducted a qualitative study with a purposive sample of individuals having conduct disorder. Focus Group Discussions (FGDs) and in-depth interviews were conducted with the participants. This approach enhanced content validity (Nunnally, 1978) as they were considered experts in their own right. The discussions in the FGD centered on both cognitive and cultural barriers to conduct disorder to either parents, children, friends and colleagues. The interviews were recorded, translated and transcribed. From thematic analysis of the FGD, four basis contents emerged: (i) emotional factor, (ii) cultural factor, (iii) behavioral factor, (iv) interpersonal factor. Items were generated with these factors resulting is more than 20 items/questions. The themes generated were then pre-testing. According to the DSM-5 Criteria, Drug Abuse was not considered directly as components of CD (American Psychiatric Association, 2015). However, in Africa context delinquency there is an age limit for individuals to take alcohol or smoke, so by implication alcoholism among adolescents (below 19 years) individuals. The item developed for this construct was considered to fit in for violation of rules for the DSM criteria.

Face validation of the scale: This was assessed to determine if the questionnaire contained relevant items for assessing Brief Propensity Index for Conduct Disorder (BPI-CD) in Africa local context especially in Nigeria. Three clinical Psychologist, two social psychologist, two correctional home personnel as well as four psychology students familiar with conduct disorder were given the items to ascertain whether the truly measure conduct behaviour. They were asked to evaluate the relevance, clarity and conciseness of the items included in the questionnaire. There was a consensus agreement among the respondents that the questions measured conduct disorder. Based on this initial assessment, all 20 items were retained.

Content Validity: An exploratory factor analysis was applied to explore the underlying dimensions of factors on (BPICD). The initial analysis revealed a dimension structure with poor factor loadings as well as the need for the subscales and the overall reliability coefficient for the whole scale ((BPI-CD)). After the deletions of the item with poor factors loadings, the 5-items remaining achieved a After the deletions of items with poor factors loadings, the 5-items (the highlighted words in red was repeated) remaining achieved a significant Bartlett test of sphericity $(\mathrm{p}<$. 0.001) and the KaiserMeyer measure of meritorious sampling adequacy suggest that the data matrix could be factorized $(\mathrm{KMO}=.685$, df $=171$, $\mathrm{p}<.001)$. There were 6 eigenvalues components greater than 1.0. for the Brief Propensity Index for Conduct Disorder (BPICD). The six components accounted for $65.86 \%$ of the total variance in the overall Brief Propensity Index for Conduct Disorder (BPI-CD). Rotated Component matrix revealed a six dimensions component. The component loading for the items range is within acceptable range $<0.70$ which indicated that all the items loaded well on the components precipitated.

\section{Procedure}

This study was approved by Faculty of Social Sciences Ethical Board, University of Ilorin. After the approval from the authorities of the selected schools, participants were selected purposively using simple randomization. College students with 
records of delinquency and juveniles were administered a tally with "Yes" and "No", those who picked "Yes" tally and signed the informed consent form were then administered the questionnaires. Data were collected in 5 public schools and one correctional institution in Ilorin metropolis. Questionnaires were administered collectively in classrooms and the researchers waited to collect them. It took 5-11minutes to complete the questionnaires.

\section{Design}

This study adopted a mixed method. It was conducted in two phases; the first phase was a qualitative study where one Key Informant Interview (KII) and three Focus Group Discussions (FGD) were conducted using juveniles and college students. While the second phase was a cross-sectional survey where the structured questionnaires of BPI$\mathrm{CD}$ were administered to 125 participants to analyse the validity and reliability of the new scale.

\section{Results}

The Brief Propensity Index for Conduct Disorder (BPI-CD) was subjected to the eight (8) comprehensive and standard procedures of new scale validation thus:

\section{Condition 1: Item-Total Statistics}

The number of valid cases for this set of variables are 125 respondents. None of the imputed items of the BPI-CD is below the recommended 0.30 minimum reliability; this indicates that none of the identified items load reduced the Cronbach's Alpha value of the scale (Keith, 2018). This suggest that all items have strong relationship with the total scale therefore, they are retained and subjected to factor analysis (see table 1 under appendix).
Condition 2: Correlation Matrix (Appropriateness: Presence of substantial correlations)

Principal components analysis requires that there be most correlations greater than 0.30 between the variables included in the analysis. For this set of items, there are sufficient correlations in the matrix greater than 0.30 , satisfying this requirement (see table 2 under appendix).

\section{Condition 3: KMO and Bartlett's Test (Sampling adequacy of individual variables)}

Principal component analysis requires that the Kaiser-Meyer-Olkin Measure of Sampling Adequacy (MSA) should be greater than 0.50 for each individual variable as well as the set of variables. On the output, the MSA for 19 items included in the analysis was greater than 0.5, supporting their retention. In addition, the overall MSA for the set of variables included in the analysis was 0.685 , which exceeds the minimum requirement of 0.50 for overall MSA (see table 3 under appendix).

\section{Condition 4: KMO and Bartlett's Test table (Bartlett test of sphericity)}

Principal component analysis requires that the probability associated with Bartlett's Test of Sphericity be less than the level of significance. The probability associated with the Bartlett test is <0.001, which satisfies this requirement (see table 3 under appendix).

\section{Condition 5: Total variance explained the Number of Factors to Extract}

Using the output, there were 6 eigenvalues components greater than 1.0. The latent root criterion for number of factors to derive would indicate that there were 6 components to be extracted for these variables. In addition, the cumulative proportion of variance criteria can be met with 6 components to satisfy the criterion of 
explaining approximately $65.86 \%$ or more of the total variance. A 6 components solution would explain $65.86 \%(\sim 66 \%)$ of the total variance (see table 4 under appendix).

\section{Condition 6: Evaluating communalities}

Table 5 of Communalities represent the proportion of the variance in the original variables that is accounted for by the factor solution. The factor solution explains at least half of each original variable's variance, so the communality value was satisfactory for all items since all the communality values was greater than 0.50 . Items $4,5,11,12 \&$ 19 were removed because they do not fulfill the requirements for the communality value considering the results in table five (5), (see table 5 under appendix).

Condition 7: Results in table 6 is Identifying the complex structure (see table 6 under appendix).

Complex structure occurs when one variable has high loadings or correlations $(0.40$ or greater) on more than one component. Three (3) of the items highlighted in table 7 and 8 demonstrated complex structure. It was therefore necessary to review the three items because of its complex

structure.

\section{Condition 8: Variable loadings on components}

The 6 components in the analysis had more than one item loading on each of them. Item 5 and 19 may need to be removed because they are loading on more than one component. Also, item 8 because it is not loading on any of the components. It suggests that they are complex to grasp by respondents (see table 6 under appendix)..

\section{Condition 9: Cronbach Alpha Reliability}

In order to ascertain a high Cronbach's Alpha coefficient that will be acceptable for (BPI-CD), the initial items were 19 items with Cronbach's Alpha 0.61, in which item 12 was deleted and the Cronbach's Alpha was increased to 0.68 (see table 7). Item 11 was further deleted and the Cronbach's Alpha consequently was 0.71 . (see table 7). Approximately, the Cronbach's Alpha arrived at 0.71. While further deletion of items 4,5,12, and 19 (see table 7) led to reduction of the Cronbach's Alpha to 0.59. Reliability value for new scale should be within acceptable range of .60 to .70 . That is, the Alpha coefficient for the new items is strong, suggesting high internal consistency (Clark \& Watson, 1995). Therefore, the items were recovered thus; 1,2,3,6, and 7 were retained for "Hostility/Aggression to People and Animals" with $\alpha$ coefficient of .76. Items 9 and 10 were retained for "deceitfulness and theft" with $\alpha$ coefficients of 0.68 while items $13,14,15,16,17$ and 18 were retained for "Serious Violation of rules" with $\alpha$ of .73. BPI-CD Brief Screening Index for Conduct Behaviour, discriminant validity was done with Youth Deviant Behavior Variety Scale of Sanches, Gouveia-Pereira, Marôco, Gomes, \& Roncon, 2016). Table above showed a significant relationship between BPI-CD and Discriminant Validity $(\mathrm{r}=.338, \mathrm{p}>.01)$, thus showing a strong convergent validity.

Table 11 above showed that participants' age brackets ranged from 10 to 19 years; male Juveniles had 53.23 while those from general population had 41.50; also, female Juveniles had 44.68 whereas females from general population had 34.78 as norms. However, the generic norms for the juveniles was 52.80 while that of general population was 48.69 .

\section{Discussion, Conclusion and Recommendations}

\section{Discussion}

The aim of this study was to develop, validate and evaluate a culturally appropriate 
measure of a Brief Propensity Index for Conduct Disorder (BPI-CD) in Nigeria and for use across Africa. Using a rating scale model and a conventional systematic approach to tool development (Dimitrov, 2012). The researcher developed a 19-item Brief Screening Index for Conduct Behaviour; (BPI-CD) in which 14items were proven reliable and valid.

The Cronbach's alpha was employed in assessing the level of acceptability of the observed values of reliability coefficients. The alpha coefficient was high for the overall items, and good reliability was observed for the three dimensions or sub scales. (BPI-CD) Cronbach alpha reliability at .71 $(\alpha=.706)$. Reliability value for new scale should be within acceptable range $<0.70$. i.e. the alpha coefficient for the new items is strong, suggesting high internal consistency. There was an exceptional test retest reliability observed in this study and this supported the utility and reliability of the Brief Propensity Index for Conduct Disorder (BPI-CD) among regular students (general population) and juvenile students in correctional institutions. Furthermore, the selection of culturally appropriate items through qualitative research ensured that the items were appropriate to this context.

Factor-analytic prove suggests that the scale is multi-dimensional, indicating that it measured four construct, namely; Hostility and Aggression using items: 1,2,3,6 and 7, Violation of rules using items: 13, 14, 16, 17 and 18. Note; destruction of Property subscale was clustered together with Violation of rules considering cultural factor), (iii) Deceitfulness and theft using items: 9 and 10. And items that were removed or deleted were; 4,5, 11,12 and 19. This suggests that individuals with conduct behaviour may be selective and viewed from a multi "eye" or diverse perspectives. The Cronbach alpha was employed in evaluating the level of acceptability of the observed values of reliability coefficients. The alpha coefficient was good for the overall items, so also the subscale recorded good reliability which is an indication of acceptable level of internal consistency for this new instrument.

Criterion related analysis of this study was also conducted to examine the correlation between certain components of (BPI-CD) and Discriminant Validity Scale with "Youth Deviant Behavior Variety Scale" of Sanches, et al., (2016) and demographic variables of the students in both regular students and juveniles. Results showed a strong convergent validity which indicated a positive correlation between (BPI-CD) and Youth Deviant Behavior Variety Scale (see table 10). This revealed an excellent validity in this study and this supported the utility, validity and reliability of the BPI-CD among teenagers or adolescents. Furthermore, the selection of culturally appropriate items through qualitative research ensured that the items were appropriate to this context. The means score for male was 53.3 and mean score was consequently for females was 46.7 (see table 11 under appendix). High score above the mean suggest the respondents who have greater traits or tendency for conduct disorder or delinquencies while lower scores equal or below the mean suggests low conduct disorder or delinquencies. This index can be used as assessment tool in both educational and correctional institutions, also it can be used among the general populations especially among adolescents or teenagers for both clinical and research purposes. There are some limitations to which this instrument can be used, it cannot be used as a diagnostic tool but a screening instrument, this instrument is not eligible to be administered to individual adults in correctional setting. 


\section{Conclusion}

This research work provides an insight into the distinguishing conduct behaviour between Africans and the western world as well as ascertained the development, validity and reliability of a new scale Brief Propensity Index for Conduct Disorder (BPI$\mathrm{CD})$. It was design to clinically assess the conduct disorder or antisocial social behaviour among Juveniles in both normal population and correctional institutions. Consequent analysis of the result shows that out of the developed 20-items of (BPI-CD), 14-items were proven reliable and valid. It is suggested that the (BPI-CD) be used among other population, tribes, race and nation to ascertain it generalizability.

\section{References}

Adeusi, S.O., Gesinde, A.M., Alao, A.A., Adejumo, G.O., \&Adekeye, O.A. (2015). Differential effect of behavioural strategies on the management of conduct disorder among adolescents in correctional centres in Lagos State, Nigeria. International Journal of Psychology and Counselling, 7(4), 63-68.

Agboola, A., Babalola1, E. \&Udofia, O. (2017). Psychopathology among Offenders in a Nigeria Prison. International Journal of Clinical Psychiatry, 5(1), 10-15 DOI: 10.5923/j.ijcp.20170501.02

American Psychiatric Association. (2015). Diagnostic and statistical manual of mental disorders (5th ed.), (98-99). Washington, DC: American Psychiatric Association
Clark, L. A., \& Watson, D. (1995). Constructing validity: Basic issues in objective scale development. Psychological Assessment, 7, 309. 319. Retrieved from: https://www.scirp.org/reference/Refer encesPapers.aspx?ReferenceID $=593253$

Dimitrov, D. V. (2012). Statistical Methods for Validation of Assessment Scale Data in Counseling and Related Fields. American Counseling Association, 5999, Stevenson Avenue, Alexandria, VA 22304.

Hussein, M.H. (2010). The psychometric properties of the Arabic version Children's Self-report Social Skills Scale. Department of Educational Psychology, College of Education, University of Alexandria, Egypt. Retrieved from the ERIC database. ( ED512777).

Kline, R. B. (2013). Exploratory and confirmatory factor analysis. In $\mathrm{Y}$. Petscher, C. Schatschneider, \& D. L. Compton (Eds.), Applied quantitative analysis education and the social sciences, 171-207. New York, NY, USA: Routledge.

Keith T.S (2018). The Use of Cronbach's Alpha When Developing and Reporting Research Instruments in Science Education. Research in Science Education, 48(6), 12731296.

Levine, T. R., Hullett, C. R., Turner, M. M., \& Lapinski, M. K. (2006). The desirability of using confirmatory factor analysis on published scales. Communication Research Reports, 23 ,

309-314. 
https://doi.org/10.1080/08824096.20 $\underline{10.518913}$

Norris, M., \& Lecavalier, L. (2010). Evaluating the use of exploratory factor analysis in developmental disability psychological research. Journal of Autism Development and Disorders, 40, 8-20. Retrieved from: https://mijn.bsl.nl/evaluating-the-useof-exploratory-factor-analysis-indevelopment $/ 549368$

Nunnally, J. C. (1978). Psychometric theory ( $2^{\text {nd }}$ ed.). New York: McGraw-Hill.

Nwankwo, B. O., Nwoke, E. U., Chukwuocha, U. M., Obbany, A. O., Nwoga, K.C., Iwuagu, U.O., \& Okereke, C. (2010). Prevalence and predictor of Antisocial behaviour: A cross-sectional survey of adolescents in secondary schools in Owerri municipal, South-East, Nigeria.
Pakistan Journal of socio-sciences, 7(2), 129-136.

Sanches, S., Gouveia-Pereira, M., Marôco, J., Gomes, H., \&Roncon, F. (2016). Deviant behavior variety scale: development and validation with a sample of Portuguese adolescents. Psicologia: Reflexão e Crítica, 29 (31), 1-8.

Tay, L., \& Jebb, A. (2017). Scale Development. In S. Rogelberg (Ed), The SAGE Encyclopedia of Industrial and Organizational Psychology, 2nd edition. Thousand Oaks, CA: Sage.

Worthington, R. L., \& Whittaker, T. A. (2006). Scale development research. A content analysis for recommendations for best practices. The Counseling Psychologist, 34(6), 806-838. 


\section{Appendix}

Table 1 Showing the Item-Total Statistics

\begin{tabular}{|l|r|r|r|r|r|}
\hline & $\begin{array}{c}\text { Scale Mean } \\
\text { if Item } \\
\text { Deleted }\end{array}$ & $\begin{array}{c}\text { Scale } \\
\text { Variance if } \\
\text { Item Deleted }\end{array}$ & $\begin{array}{c}\text { Corrected } \\
\text { Item-Total } \\
\text { Correlation }\end{array}$ & $\begin{array}{c}\text { Squared } \\
\text { Multiple } \\
\text { Correlation }\end{array}$ & $\begin{array}{c}\text { Cronbach's } \\
\text { Alpha if Item } \\
\text { Deleted }\end{array}$ \\
\hline bcd1 & 40.5280 & 113.993 & .512 & .583 & .038 \\
bcd2 & 40.3600 & 116.184 & .458 & .460 & .004 \\
bcd3 & 40.5920 & 117.598 & .460 & .430 & .050 \\
bcd6 & 38.6724 & 118.554 & .457 & .301 & -.013 \\
bcd7 & 40.7600 & 118.200 & .450 & .401 & -.005 \\
Bcd8 & 39.8800 & 117.816 & .341 & .373 & .023 \\
Bcd9 & 40.7680 & 118.470 & .458 & .440 & -.012 \\
bcd10 & 39.2480 & 107.494 & .454 & .410 & .013 \\
bcd13 & 39.8160 & 116.764 & .317 & .367 & .145 \\
bcd14 & 39.1280 & 117.387 & .375 & .381 & -.010 \\
bcd15 & 38.1432 & 127.124 & .381 & .370 & .006 \\
bcd16 & 40.0560 & 116.102 & .392 & .431 & .013 \\
& 40.2120 & 117.202 & .380 & .403 & .014 \\
bcd17 & 39.8000 & 116.097 & .370 & .443 & .114 \\
bcd18 & & 117.212 & & .467 & .553 \\
& & & & & \\
\hline
\end{tabular}




\begin{tabular}{|c|c|c|c|c|c|c|c|c|c|c|c|c|c|c|}
\hline bcd1 & 1 & & & & & & & & & & & & & \\
\hline bcd2 & .634 & 1 & & & & & & & & & & & & \\
\hline bcd3 & .587 & .630 & 1 & & & & & & & & & & & \\
\hline bcd6 & .047. & .191 & .173 & 1 & & & & & & & & & & \\
\hline bcd7 & .386 & .364 & .378 & .306 & 1 & & & & & & & & & \\
\hline bcd8 & -.122 & -.083 & .031 & -.159 & -.189 & 1 & & & & & & & & \\
\hline bcd 9 & .278 & .360 & .321 & .318 & .426 & -398 & 1 & & & & & & & \\
\hline bcd 10 & .511 & .445 & .427 & .161 & .593 & -.112 & .374 & 1 & & & & & & \\
\hline bcd13 & .233 & .274 & .189 & .251 & .196 & -.072 & .358 & .233 & 1 & & & & & \\
\hline bcd14 & .018 & .037 & .000 & .179 & .093 & -.243 & .274 & .078 & .202 & 1 & & & & \\
\hline bcd15 & .301 & .346 & .246 & 190 & .301 & -.229 & .374 & .353 & .608 & .176 & 1 & & & \\
\hline bcd16 & . 200 & .168 & .137 & .187 & .259 & -.127 & -.015 & .236 & .219 & .357 & .379 & 1 & & \\
\hline bcd17 & .161 & -.003 & .133 & .323 & .253 & -.178 & .029 & .217 & .175 & .364 & .284 & .715 & 1 & \\
\hline bcd18 & - & -.155 & -.043 & -.042 & .086 & -.105 & -.049 & -.047 & .027 & .206 & -.080 & .159 & .271 & 1 \\
\hline
\end{tabular}

\section{Table 2 Showing the Correlation Matrix of Inter Items}

Table 3 Showing the KMO and Bartlett's Test

\begin{tabular}{|c|c|c|}
\hline \multicolumn{2}{|c|}{ Kaiser-Meyer-Olkin Measure of Sampling Adequacy. } & $\begin{array}{r}.685 \\
839.961\end{array}$ \\
\hline \multirow[t]{2}{*}{ Bartlett's Test of Sphericity } & Df & 171 \\
\hline & Sig. & .000 \\
\hline
\end{tabular}

Table 4 Showing the Total Variance Explained

\begin{tabular}{|c|c|c|c|c|c|c|c|c|c|}
\hline \multirow{2}{*}{ 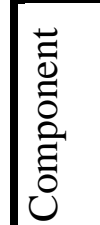 } & \multicolumn{3}{|c|}{ Initial Eigenvalues } & \multicolumn{3}{|c|}{$\begin{array}{l}\text { Extraction Sums of Squared } \\
\text { Loadings }\end{array}$} & \multicolumn{3}{|c|}{$\begin{array}{l}\text { Rotation Sums of Squared } \\
\text { Loadings }\end{array}$} \\
\hline & Total & $\begin{array}{c}\% \text { of } \\
\text { Variance }\end{array}$ & $\begin{array}{c}\text { Cumulative } \\
\%\end{array}$ & Total & $\begin{array}{c}\% \text { of } \\
\text { Variance }\end{array}$ & $\begin{array}{c}\text { Cumulative } \\
\%\end{array}$ & Total & $\begin{array}{c}\% \text { of } \\
\text { Variance }\end{array}$ & $\begin{array}{c}\text { Cumulative } \\
\%\end{array}$ \\
\hline 1 & 4.402 & 23.170 & 23.170 & 4.402 & 23.170 & 23.170 & 3.211 & 16.902 & 16.902 \\
\hline 2 & 2.551 & 13.426 & 36.597 & 2.551 & 13.426 & 36.597 & 1.996 & 10.504 & 27.406 \\
\hline 3 & 1.714 & 9.023 & 45.619 & 1.714 & 9.023 & 45.619 & 1.942 & 10.223 & 37.629 \\
\hline 6 & 1.072 & 5.644 & 65.858 & 1.072 & 5.644 & 65.858 & 1.707 & 8.986 & 65.858 \\
\hline 7 & .958 & 5.043 & 70.901 & & & & & & \\
\hline 8 & .924 & 4.864 & 75.765 & & & & & & \\
\hline 9 & .774 & 4.074 & 79.839 & & & & & & \\
\hline 10 & .662 & 3.482 & 83.321 & & & & & & \\
\hline 13 & .397 & 2.091 & 91.279 & & & & & & \\
\hline 14 & .385 & 2.026 & 93.305 & & & & & & \\
\hline 15 & .363 & 1.910 & 95.215 & & & & & & \\
\hline 16 & .281 & 1.478 & 96.693 & & & & & & \\
\hline 17 & .251 & 1.323 & 98.015 & & & & & & \\
\hline 18 & .217 & 1.141 & 99.157 & & & & & & \\
\hline
\end{tabular}


Extraction Method: Principal Component Analysis.

Table 5 Showing Communalities

\begin{tabular}{|l|r|r|}
\hline & Initial & Extraction \\
\hline bcd1 & 1.000 & .722 \\
bcd2 & 1.000 & .730 \\
bcd3 & 1.000 & .690 \\
bcd6 & 1.000 & .754 \\
bcd7 & 1.000 & .790 \\
bcd8 & 1.000 & .541 \\
bcd9 & 1.000 & .734 \\
bcd10 & 1.000 & .634 \\
bcd13 & 1.000 & .740 \\
bcd14 & 1.000 & .600 \\
bcd15 & 1.000 & .732 \\
bcd16 & 1.000 & .738 \\
bcd17 & 1.000 & .779 \\
bcd18 & 1.000 & .784 \\
\hline
\end{tabular}

Extraction Method: Principal Component Analysis.

Table 6 Showing the Component Matrix ${ }^{a}$

\begin{tabular}{|c|c|c|c|c|c|c|}
\hline & \multicolumn{6}{|c|}{ Component } \\
\hline & 1 & 2 & 3 & 4 & 5 & 6 \\
\hline bcd1 & .667 & -.324 & .030 & 232 & -.209 & .123 \\
\hline bcd2 & .685 & -.373 & .020 & .150 & .121 & .292 \\
\hline bcd3 & .639 & -.353 & .128 & .340 & .050 & .164 \\
\hline cd6 & .458 & .252 & .076 & -.358 & .591 & -.047 \\
\hline d7 & .669 & -.103 & .069 & .061 & -.067 & -.367 \\
\hline bcd8 & .203 & -.286 & .684 & .019 & -.143 & .187 \\
\hline bcd 9 & .620 & -.163 & -.246 & -.284 & .134 & -.215 \\
\hline bcd 10 & 687 & -.226 & .104 & .102 & -.165 & -.255 \\
\hline d13 & .224 & .056 & -.081 & -.365 & -.245 & .423 \\
\hline & .341 & .555 & -.226 & -.092 & .075 & .128 \\
\hline d15 & .627 & .027 & .064 & -.460 & -.335 & .174 \\
\hline bcd 16 & .388 & .523 & .333 & .021 & -.194 & .008 \\
\hline bcd 17 & .359 & 655 & .336 & .071 & -.095 & -.111 \\
\hline bcd 18 & .031 & .559 & -.324 & .340 & -.370 & -.118 \\
\hline
\end{tabular}

Extraction Method: Principal Component Analysis. 
a. 6 components extracted.

Table 7 Showing the Reliability Statistics

\begin{tabular}{|c|c|c|c|}
\hline & Cronbach Alpha & \multicolumn{2}{|c|}{0.86} \\
\hline & Number of Items & \multicolumn{2}{|c|}{14} \\
\hline Item & $\begin{array}{c}\text { Items } \\
\text { Hostility/Aggression to People and Animals }\end{array}$ & $\begin{array}{l}\text { Corrected } \\
\text { item } \\
\text { Total } \\
\text { Correlati } \\
\text { on }\end{array}$ & $\begin{array}{l}\text { Cronba } \\
\text { ch's } \\
\text { Alpha } \\
\text { if Item } \\
\text { Deleted }\end{array}$ \\
\hline 1 & I found fun in causing troubles at home, street or school &.-110 & .001 \\
\hline 2 & Making people to fight is fun & -.093 & -.072 \\
\hline 3 & $\begin{array}{l}\text { I see nothing wrong in using weapon or harmful objects to force } \\
\text { someone to do what I want }\end{array}$ & .142 & .016 \\
\hline 6 & Killing domestic animals or harming them is no big deal & .405 & -.009 \\
\hline 7 & I like making animals or people to fight each other & .571 & -.028 \\
\hline \multirow[t]{3}{*}{8} & I can cause harm to any person without regretting it & .348 & -.024 \\
\hline & Cronbach Alpha for this subscale $=0.76$ & & \\
\hline & Deceitfulness/Theft & & \\
\hline 9 & $\begin{array}{l}\text { In the past I have taken something that belongs to another without } \\
\text { them knowing }\end{array}$ & .018 & -.010 \\
\hline \multirow[t]{3}{*}{10} & There is nothing wrong in stealing to get what I want & .046 & -.016 \\
\hline & Cronbach Alpha for this subscale $=0.68$ & & \\
\hline & Serious Violations of Rules & & \\
\hline 13 & My parent or guardian do complain of my keeping late night & .049 & -.017 \\
\hline 14 & $\begin{array}{l}\text { I have stayed with friends/someone when I'm supposed to be in } \\
\text { school at least twice or more }\end{array}$ & .335 & .009 \\
\hline 15 & Looking at my behaviour, friends call me a smart guy/girl & .125 & -.038 \\
\hline 16 & I have left home for a long period before without informing anybody & .436 & .787 \\
\hline 17 & I believe that smoking makes someone to be sharp and high in action & .398 & .024 \\
\hline \multirow[t]{2}{*}{18} & I have never been arrested or invited to the police station before & .041 & -.021 \\
\hline & Cronbach Alpha for this subscale $=.73$ & & \\
\hline
\end{tabular}


Table 9, Showing the Pearson Correlation of BPI-CD and Deviant Variety Scale Indicating the Convergent Validity

\begin{tabular}{|ll|r|r|}
\hline & DV.Total & bcd.Total \\
\hline \multirow{2}{*}{ DV.Total } & Pearson Correlation & 1 & $-.338^{* *}$ \\
& Sig. (2-tailed) & & .000 \\
& $\mathrm{~N}$ & 125 & 125 \\
& Pearson Correlation & $-.338^{* * *}$ & 1 \\
bcd.Total & Sig. (2-tailed) & .000 & \\
& $\mathrm{~N}$ & 125 & 125 \\
\hline
\end{tabular}

**. Correlation is significant at the 0.01 level (2-tailed).

Table 10 of Pearson Correlation of BPI-CD and Social Skills Scale Indicating the Discriminant Validity

\begin{tabular}{|rr|c|r|}
\hline & & SS.Total & bcd.Total \\
\hline \multirow{3}{*}{ SS.Total } & Pearson Correlation & 1 & -.101 \\
& Sig. (2-tailed) & & .261 \\
& $\mathrm{~N}$ & 125 & 125 \\
bcd.Total & Pearson Correlation & -.101 & 1 \\
& Sig. (2-tailed) & .261 & \\
$\mathrm{~N}$ & 125 & 125 \\
\hline
\end{tabular}

Table 11, of (BPI-CD) Showing Juvenile, General Population and Generic Norms with Gender Consideration

\begin{tabular}{|l|c|c|}
\hline \multicolumn{1}{|c|}{ NORM(S) } & Juvenile Population & General Population \\
\hline Age & $10-19$ & $10-19$ \\
\hline Male & 53.23 & 41.50 \\
\hline Female & 44.68 & 34.78 \\
\hline Generic Norm & 52.80 & 48.69 \\
\hline
\end{tabular}

